\title{
Probable Values of Conventional Allowance for A-C. Generator Stator Windings
}

\author{
BY F. D. NEWBURY \\ Fellow, A. I. E. E. \\ Manager, Power Engineering Department, \\ Westinghouse Electric and Manufacturing Co.
}

$\mathrm{T}$ HE principle employed in the A.I. E. E. Standards for determining the limiting temperature rises as a basis for rating is the so-called hottest-spot principle. The hottest-spot temperature is the bench mark or original point of reference and the limiting observable temperature is derived from it by subtracting a temperature that represents the difference between this temperature and the highest temperature that it is possible to measure by commercial methods. This difference is known in the A. I. E. E. Standards, as the "conventional allowance."

This basis for determining limiting observable temperatures can scarcely be criticized on theoretical grounds. It has been criticised, however, and with reason, because of the practical difficulties attending the evaluation of the conventional allowance. These practical difficulties have been greatly increased by the conception of the conventional allowance as an attribute of the method of measurement alone, resulting in a single conventional allowance for each recognized method of measurement.

Experience in building up standards under this principle has shown that it is impossible for a single value to satisfy all the practical situations arising. The conventional allowance with a certain method of measurement will vary with the total temperature or temperature rise; this has led to the suggestion that different values of conventional allowance be assigned for the different temperature limits of the different classes of insulation. But, even with a given method of measurement and a given limiting temperature the proper conventional allowance may still vary considerably because of the widely different conditions existing in different applications. For example, a conventional allowance for the thermometer method of measurement (with Class A Insulation temperature limits) may vary considerably in these several applications: A small induction motor stator winding, a large wire-wound shunt field coil, or an air-blast transformer winding. Or, to consider another class, the conventional allowance for the resistance method of measurement (with Class B insulation temperature limits) may vary considerably in a turbine type generator rotor winding and in a relatively small railway motor armature winding.

A consideration of these facts has led many engineers away from the idea of a single value of the conventional allowance applicable to a given method of measurement

Presented at the Annual Convention of the A. I. E. E., Niagara Falls, Ontario, June 26-90,1922. toward the idea of a conventional allowance associated with a single particular application. The former conception made the values of conventional allowance general in their application and the numerical values naturally became a part of the principle. The latter conception makes the values limited and specific in their use and divorces them from the general principle; this strengthens both the principle and the application of the principle to practical cases.

The work described in this paper has been based on this second conception of the conventional allowance. It has been attempted to determine experimentally the value of the conventional allowance for this particular method of measurement when applied to a given class of alternating-current machine stator windings for given temperature limits.

This experimental work has been of two kinds: First, the measurement in machines of various sizes and voltages of copper temperatures by detectors inside the coil insulation) and of "observable" temperatures (by detectors located between the two coil sides in a slot) thus determining, by direct measurement, the data on which values of conventional allowance can be based; and second, an investigation of the influence of various factors such as insulation thickness, eddy current losses, core length and core temperature on the conventional allowance, by using a small armature model in which these several factors can be varied conveniently.

The tests on generators have been carried out under the direction of the Subcommittee on Rotating Machinery of the Standards Committee and the author acknowledges, with pleasure, his indebtedness to the Committee for permission to publish this information. Mr. C. J. Fechheimer is responsible for the interpretation of the model test results and the development, therefrom, of the formulas for the calculation of values of conventional allowance and top-coil copper temperatures.

\section{MODEL TESTS}

In Figs. 1 and 2 are shown the details of a model designed to reproduce the temperature conditions in a radially ventilated armature core.

Thermocouples are distributed throughout the coils and core as indicated, so as to measure the true copper temperature, the temperature between coils and the average tooth temperature.

The several factors whose influence on the conventional allowance it is desired to study were reproduced as follows: 
1. In order to imitate the conditions that obtain in a long machine, the coil ends were blocked so that the cooling of the ends by forced convection was very

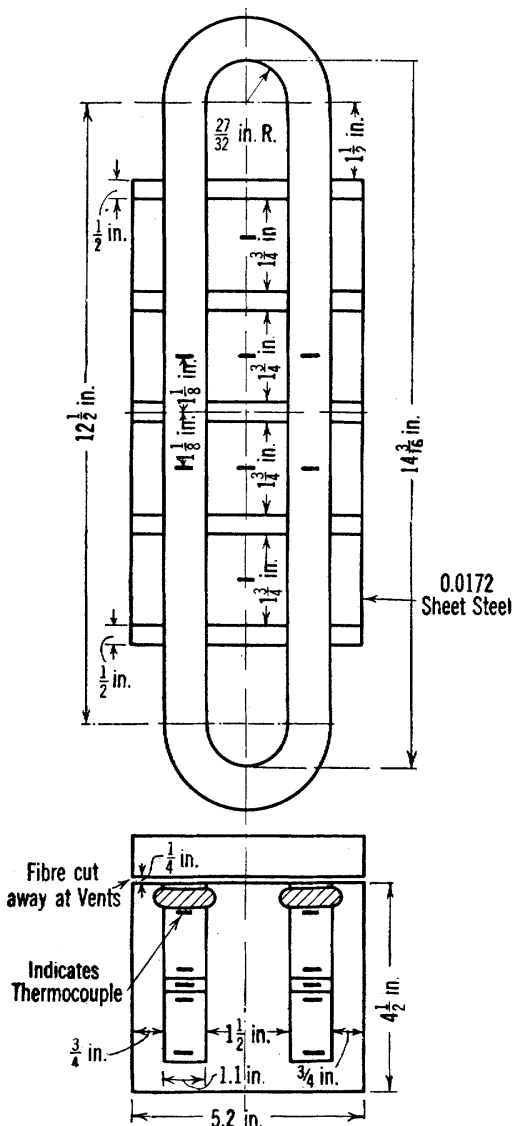

FIG. 1

Two coils, each consisting of eighty turns of 0.095 -in. by 0.122 -in. d. c. c. arranged 8 by 0.095 in. wide.

small. Thermocouples in the ends then showed nearly the same temperature as the copper in the embedded part, and therefore the longitudinal heat flow was negligible, thus simulating conditions that obtain at

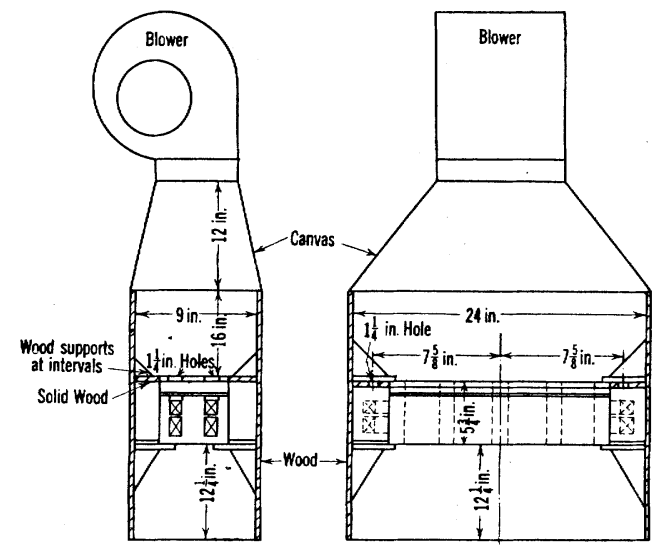

FIG. 2

the middle of a long-core machine. The short-core machine was imitated by opening the coil ends to the ventilating air streams.
2. The temperature of the iron was altered by changing the speed of the blower supplying the cooling air. By this means the iron temperature rise was changed from 10.5 to $70 \mathrm{deg}$. rise for the long-core, or from 9 to $40 \mathrm{deg}$. rise for the short-core machine, with the same current in the coils.

3. In all tests, direct current was used in the two coils. In order to imitate the influence of eddy currents the value of current in the upper coil was changed, the current in the lower coil being kept substantially constant throughout the tests.

4. The coil insulation was nominally for 6600 volt wrapper but it was crowded into a smaller space than is ordinarily used for that voltage. The wall thickness was approximately 0.11 in. Extra insulation was placed between coils, as shown in Fig. 3. The extra insulation was about 0.32 in. thick, thus making the equivalent wall thickness $\frac{0.32}{2}+0.11=0.27$ in, or

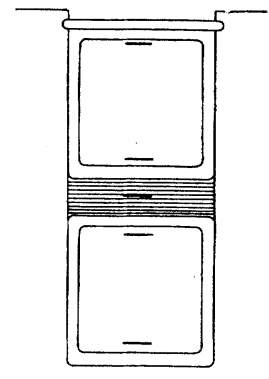

Fig. 3

slightly greater than would be used for 13,200 volts. Tests were made with and without this extra insulation.

Twenty eight different temperature tests were made under various conditions; the first series was equivalent to a 13,200-volt long-core generator with varying eddy current losses (varying loss ratio) and with varying core temperatures; similar series of tests were made for a 6600-volt long-core armature and for 13,200-volt short-core armatures. All temperature tests were continued until steady temperatures were attained. The test results of all runs are summarized in Table I and the results of typical runs are plotted in the accompanying curves.

Fig. 4 shows the variation in temperature rises for different blower speeds, equivalent to different core temperatures, with 20 amperes in each coil and imitating the long-core machine. (The reciprocals of blower speeds are used as abscissas in order that the curves approach straight lines). It will be seen that the maximum copper temperature and iron temperature curves are nearly parallel, indicating that although the iron temperature rise increased from $10.5 \mathrm{deg}$. to $70 \mathrm{deg}$. the drop from the copper to the iron changed but little; and this small increase was largely due to the increase in copper temperature with resistance. This relation is to be expected from the fundamentals 
TABLE I

SUMMARY OF TESTS ON ARMATURE MODEL

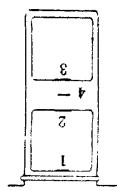

\begin{tabular}{|c|c|c|c|c|c|c|c|c|c|c|c|c|c|}
\hline $\begin{array}{l}\text { Long or } \\
\text { short core }\end{array}$ & $\begin{array}{c}\text { Extra ins. } \\
\text { bet coils }\end{array}$ & $\begin{array}{l}\text { Fan rev. } \\
\text { per min. }\end{array}$ & $\begin{array}{l}\text { Amps. } \\
\text { top coil }\end{array}$ & $\begin{array}{c}\text { Amps. } \\
\text { bot. coil }\end{array}$ & $\begin{array}{c}\text { Loss } \\
\text { Ratio }= \\
(I \text { top } I \text { bot. })\end{array}$ & $\begin{array}{l}\text { Temp. } R \\
\text { Pos } 1\end{array}$ & $\begin{array}{cc}\text { Temp. } & R \\
\text { Pos. } 4 & \theta m\end{array}$ & $\begin{array}{l}\text { Temp. } R \\
\text { Iron } \theta i\end{array}$ & $\underset{\text { Air }}{\text { Temp. } R}$ & \begin{tabular}{|c|} 
Mean of \\
temp. Pos \\
$(2) \&(3)$
\end{tabular} & $\left|\begin{array}{c}\text { Mean of } \\
2 \text { and } 3 \mathrm{H} \\
-4=\theta a\end{array}\right|$ & $\left|\begin{array}{c}\text { Test top } \\
\text { coil temp. } \\
\text { rise Pos. } 2\end{array}\right|$ & $\begin{array}{c}\text { Test bot } \\
\text { coil temp. } \\
r . \text { Pos. } 3\end{array}$ \\
\hline Long & Yes & 150 & 20 & 20 & 1. & 110 & 97 & 70 & 20 & 115.5 & 18.5 & 115 & 116 \\
\hline " & “ & 200 & “ & $"$ & $"$ & 89 & 78 & 53 & 12 & 96 & 18.0 & 96 & 96 \\
\hline " & “ & 300 & “ & $"$ & " & 73 & 60 & 37 & 9 & 78 & 18.0 & 78 & 78 \\
\hline 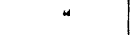 & $"$ & 600 & $"$ & “ & $“$ & 57 & 43 & 22 & 6 & 61 & 18.0 & 61 & 61 \\
\hline " & " & 900 & “ & $“$ & “ & 49.5 & 34.5 & 16.5 & 4.5 & 53.5 & 19.0 & 53.5 & 53.5 \\
\hline$"$ & $"$ & 1400 & $"$ & " & “ & 40.5 & 24.5 & 10.5 & 2.0 & 43.5 & 19.0 & 43.5 & 43.5 \\
\hline " & $"$ & 300 & $2 \tilde{5}$ & 20 & 1.56 & 121.5 & 89.5 & 52.5 & 12.5 & 112.5 & 23 & 128.5 & 96.5 \\
\hline$"$ & $"$ & 1400 & 20 & $"$ & 1.0 & 43 & 27 & 11.0 & 2.2 & 46 & 19 & 45 & 47 \\
\hline$"$ & " & “ & 25 & $"$ & 1.56 & 69 & 38 & 17 & 3.2 & 60 & 22 & 71 & 49 \\
\hline " & " & “ & 28 & $"$ & 1.96 & 89 & 47 & 20 & 4.0 & 71.5 & 24.5 & 90 & 53 \\
\hline$"$ & No. & 1400 & 20 & 20 & 1.00 & 42 & 40 & 11 & 4.0 & 48 & 8.0 & 47 & 49 \\
\hline$"$ & “ & " & 25 & $"$ & 1. 56 & 66.5 & 55.5 & 14.5 & 6.3 & 63 & 7.5 & 71.5 & 54.5 \\
\hline " & “ & " & 27.5 & $"$ & 1. 89 & 84.0 & 69.0 & 19 & 8.0 & 76 & 7.0 & 91.0 & 61.0 \\
\hline “ & " & 600 & 20 & 20 & 1.00 & 61.0 & 63 & 28 & 12.25 & 69.75 & 6.75 & 68 & 71.5 \\
\hline$"$ & “ & “ & 25 & $"$ & 1. 56 & 88.5 & 83.5 & 30.5 & 13.5 & 88.0 & 5.50 & 97.5 & 78.5 \\
\hline “ & “ & “ & 27.5 & $"$ & 1. 89 & 114.5 & 104.5 & 40.5 & 19.0 & 108.5 & 4.00 & 125.5 & 91.5 \\
\hline “ & “ & 300 & 20 & 20 & 1.00 & 82.5 & 86.5 & 45.5 & 22.0 & 92.0 & 5.5 & 91.5 & 92.5 \\
\hline$"$ & $"$ & $"$ & 24.7 & 19.4 & 1.62 & 124.5 & 118.5 & 60.5 & 32.5 & 121.5 & 3.0 & 133.5 & 109.5 \\
\hline “ & $"$ & $"$ & 27.5 & 19.6 & 1.97 & 149.5 & 139.5 & 70.5 & 35.5 & 144.5 & 5.0 & $164.5^{\circ}$ & 124.5 \\
\hline Short & Yes & 150 & 20 & 20 & 1.00 & 66 & 59 & 40 & 11 & 71.5 & 12.5 & 70 & 73 \\
\hline " & " & 230 & $"$ & $"$ & $"$ & 55 & 47 & 30 & 8.5 & 60.0 & 13.0 & 58 & 62 \\
\hline$“$ & $“$ & 310 & “ & “ & " & 48 & 41 & 24 & 6.8 & 52.5 & 11.5 & 51 & 54 \\
\hline “ & “ & 400 & " & “ & $"$ & 44 & 36 & 20 & 5.0 & 47.5 & 11.5 & 46 & 49 \\
\hline$*$ & “ & 600 & $"$ & $"$ & $“$ & 39 & 31 & 15 & 3.2 & 42.5 & 11.5 & 41 & 44 \\
\hline$"$ & “ & 1400 & $a$ & $"$ & " & 33 & 22 & 9 & 2.0 & 36 & 14.0 & 35 & 37 \\
\hline$"$ & $"$ & $"$ & 25 & " & 1.56 & 50 & 31 & 13 & 2.5 & 46.5 & 15.5 & 55 & 38 \\
\hline$"$ & $“$ & $"$ & 24.5 & 20.8 & 1.50 & 49.5 & 31.5 & 11.5 & 2.5 & 46.0 & 14.5 & 53.5 & 38.5 \\
\hline “ & " & $"$ & 27.5 & 20.0 & 1.90 & 60.0 & 36.0 & 13 & 2.8 & 52.0 & 16 & 65.0 & 39 \\
\hline
\end{tabular}

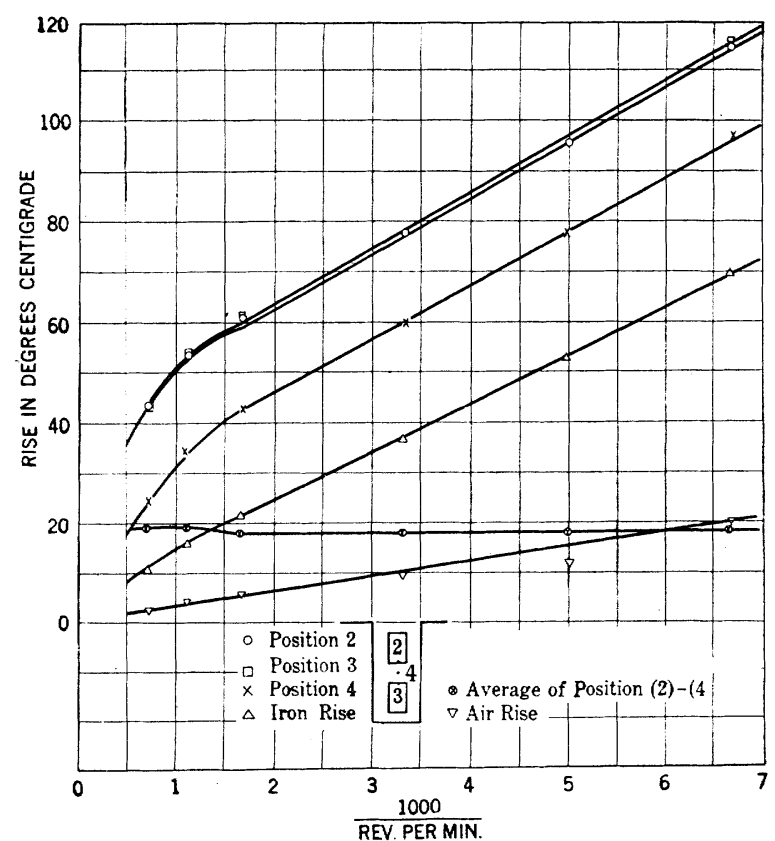

Fig. 4-Temperature Rise as a Function of Reciprocal of Fan Rev. Per Min.

Twenty amperes d-c in both coils. Ends poorly ventilated. Long core . machine. $1 / 4$ in. extra insulation between coils. of heat flow and temperature drop. This is the first important fact to be observed.

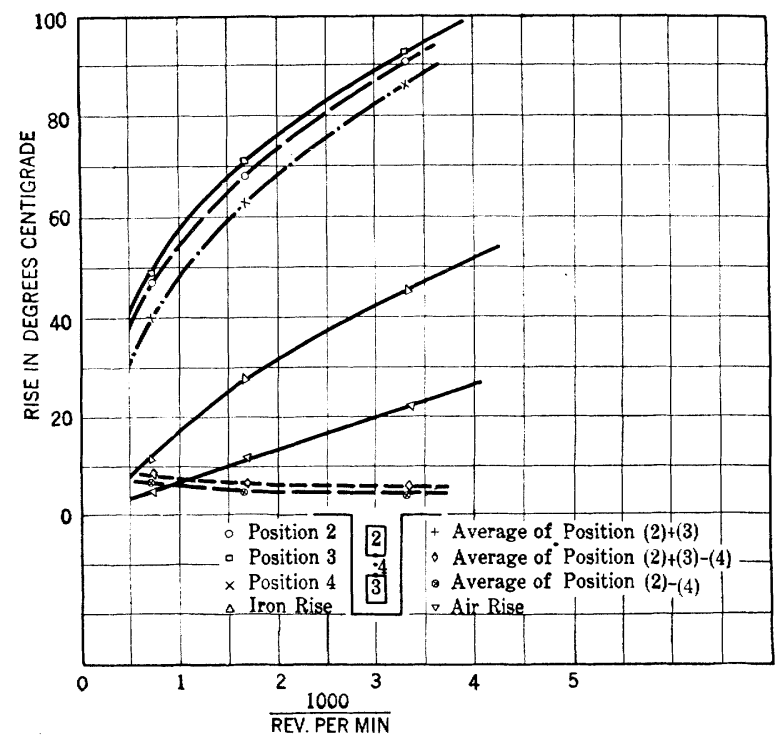

Fig. 5-Temperature Rise as a Function of Reciprocal of Fan Rev. Per Min.

Twenty amperes d-c. in both coils. Ends poorly ventilated. Long core machine. No extra insulation between coils.

The second important fact may be noted from Figs. 4,5 , and 6 viz., the amount or velocity of cooling air 
has no effect upon the total temperature drop through the insulation, or on the difference between copper and observable temperatures, (if allowance is made for the increase in resistance with temperature). It follows,

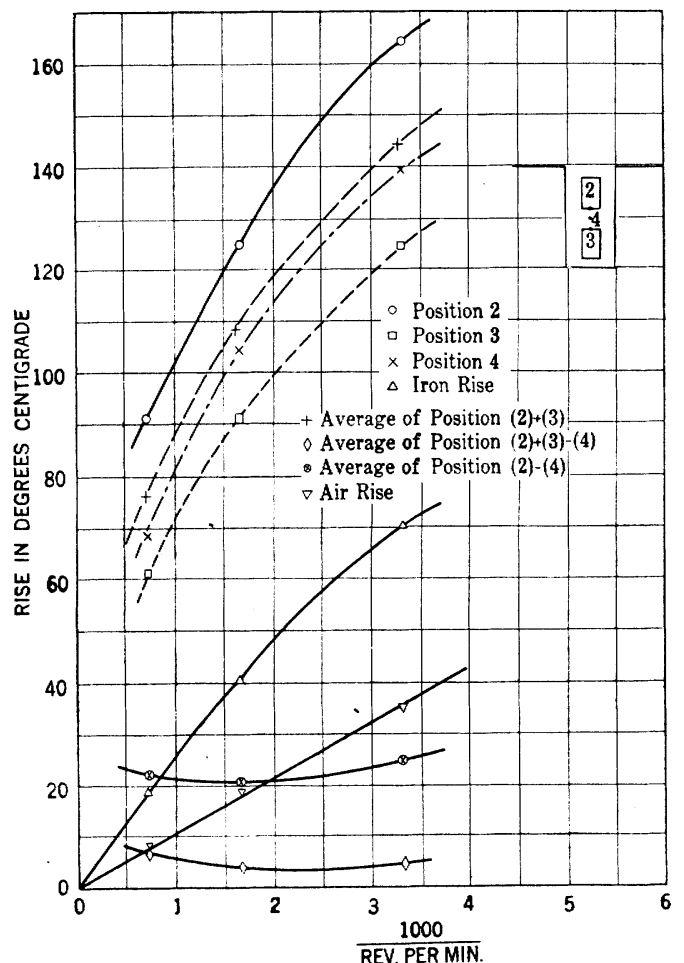

Fig. 6-Temperature Rise as a Function of Reciprocal of Fan Rev. Per Min.

Twenty amperes d-c. in lower coil. 27.5 amperes d-c. in upper coil. Ends poorly ventilated. Long core machine. No extra insulation between coils.

that changes in armature temperatures caused by changes in ventilation are not accompanied by any changes in conventional allowances.

The third important fact is that there is substantially a constant difference between the mean of the top and bottom coil temperatures and the observable temperature rise (detector between coils,) provided the loss in the bottom coil is not altered and the insulation thickness is fixed. This may be seen to hold with reasonable accuracy whether or not the ventilation (or iron temperature) change through wide limits; whether or not the eddy current loss be materially changed; Figs. 7 and 8; whether the wall of insulation be thin or thick (provided it is not changed during a series of tests); or if the core be long or short. This fact is interesting and of value, and to our knowledge has not been pointed out by any one previous to this investigation. This temperature difference, it should be noted, exists in spite of equal temperatures in top and bottom coils. We have been accustomed to think that under this condition of equal coil temperature, the observable temperature is equal to the copper temperature. Such, however, is not the case because there is heat flow to the slot sides from the adjacent sides of the coils and from this series of tests a measure of the temperature drop caused by this flow was ob- tained. Thus, (see Table I) this drop for the same current in both coils, was 18 to $19 \mathrm{deg}$. for iron temperature rises of $10.5 \mathrm{deg}$. to $70 \mathrm{deg}$., (with extra insulation between coils); and was $10.5 \mathrm{deg}$. to $13 \mathrm{deg}$. for variations in iron temperature rises from $9 \mathrm{deg}$. to $40 \mathrm{deg}$. (for no extra insulation between coils). With variations in loss ratio, for a given insulation and core length, the change in this drop is slightly greater, but still can be considered as constant with reasonable accuracy.

These relations are used in deriving the equations for calculating the conventional allowance. Let $\theta_{t}=$ the temperature rise of the copper in the top coil $\theta_{b}=$ the temperature rise of the copper in the bottom coil

$\theta_{m}=$ the temperature rise by detector between coil sides

$\theta_{a}=$ the temperature difference between the means of top and bottom coil temperatures and the temperature by detector between coils. This is equivalent to the drop in temperature due to heat flow to the slot sides (between coils) and is constant under certain conditions.

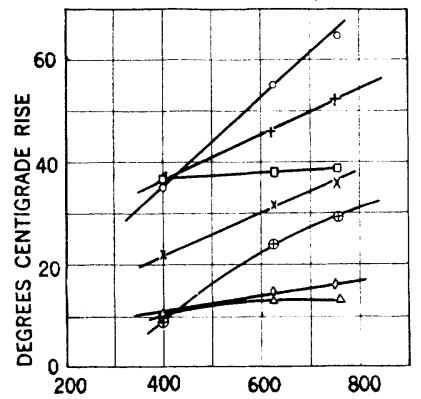

Tests at 1400 rev. per min. of fan. Twenty amperes $d-c$, in lower coil in all tests. Temperature rises as a function of square of current in upper coil. $1 / 4$ in. extra insulation between coils.

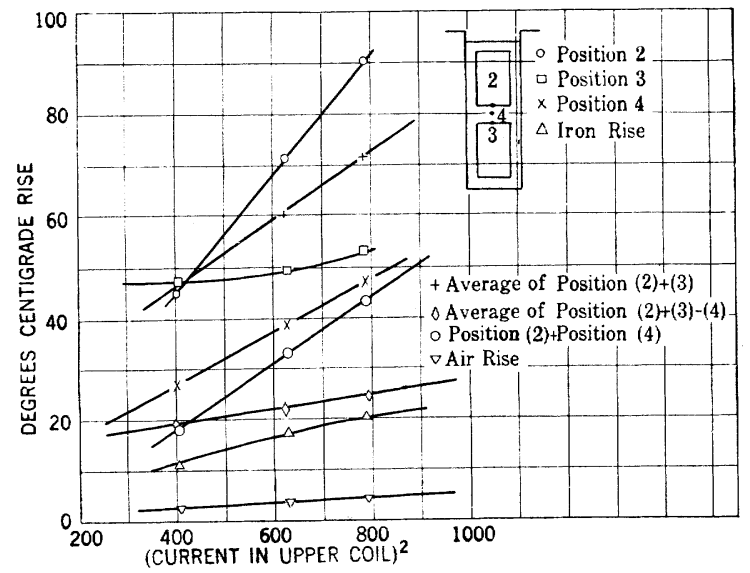

Ends poorly ventilated. Long core machine.

Fig. 7

By definition

$$
\theta_{a}=\frac{\theta_{t}+\theta_{b}}{2}-\theta_{m}
$$

It is reasonable to assume that the temperature rises of the top and bottom coils above the temperature of 
the adjacent core teeth is proportional to the losses in these coils; the ratios of these temperature rises will be equal to the ratio of the losses. The loss in each

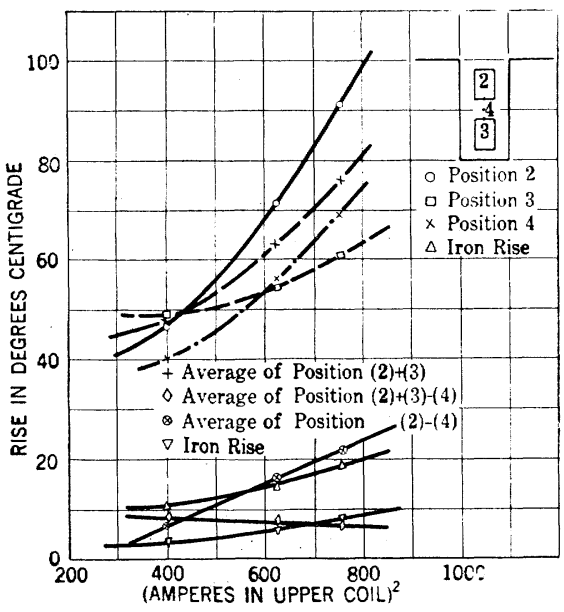

Fig. 8-Temperature Rise as a Function of Square of Current in Upper Coll

Current in lower coil constant equals twenty amperes. Fan speed constant equals 1400 rev. per min. Ends poorly ventilated. Long core machine. No extra insulation between coils. ratio of coil losses be designated by $L . R$. and the core tooth temperature by $\theta_{i}$; then:

$$
\text { L. R. }=\frac{\theta_{t}-\theta_{i}}{\theta_{b}-\theta_{i}}
$$

In the usual case, $\theta_{i}$ and $\theta_{m}$ are measured, and the constant $\theta_{a}$, is determined by test on similar apparatus. The loss ratio may be estimated from eddy-current calculations. We then have two equations, and two unknowns, $\theta_{b}$ and $\theta_{t}$. Solving for them,

$$
\begin{aligned}
& \theta_{b}=\frac{2\left(\theta_{m}+\theta_{a}\right)+\theta_{i}(L . R .-1)}{L . R .+1} \\
& \theta_{t}=\frac{2 L . R .\left(\theta_{m}+\theta_{a}\right)-\theta_{i}(L . R .-1)}{L . R .+1}
\end{aligned}
$$

Also from (1)

$$
\left(\theta_{b}+\theta_{t}\right)=2\left(\theta_{m}+\theta_{a}\right)
$$

The conventional allowance is

$$
\theta_{c}=\theta_{t}-\theta_{m}=\frac{\left(\theta_{m}-\theta_{i}\right)(L . R .-1)+2 \theta_{a} L . R .}{L . R .+1}
$$

\begin{tabular}{|c|c|c|c|c|c|c|c|c|c|c|c|c|c|c|c|}
\hline $\begin{array}{l}\text { Long } \\
\text { or short } \\
\text { core }\end{array}$ & $\begin{array}{l}\text { Extra } \\
\text { Ins. } \\
\text { bet. } \\
\text { coils }\end{array}$ & $\begin{array}{l}\text { Fan } \\
\text { rev. per } \\
\text { min. }\end{array}$ & $\begin{array}{l}\text { Amps. } \\
\text { top coil }\end{array}$ & $\begin{array}{c}\text { Amps. } \\
\text { bot. coil }\end{array}$ & $\begin{array}{c}\text { Value } \theta \text { a } \\
\text { used in } \\
\text { formula }\end{array}$ & $\begin{array}{l}\text { Value of } \\
\theta i \text { in } \\
\text { formula }\end{array}$ & $\begin{array}{c}\text { Value of } \\
L R \text { in } \\
\text { formula }\end{array}$ & $\begin{array}{c}\text { Calc. top } \\
\text { coil } \\
\text { temp. } \\
\text { rise }\end{array}$ & \begin{tabular}{|c|} 
Test top \\
coil \\
temp. \\
rise for \\
pos. 2
\end{tabular} & $\begin{array}{c}\text { Calc. } \\
\text { bot. coil } \\
\text { temp. } \\
\text { rise } \\
\text { pos. } 3\end{array}$ & \begin{tabular}{|c|} 
Test bot. \\
coil \\
temp. \\
rise \\
pos. 3
\end{tabular} & $\begin{array}{l}\text { Calc. } \\
\text { conv. } \\
\text { allow- } \\
\text { ance } \\
\theta c a\end{array}$ & $\begin{array}{c}\text { Test } \\
\theta<a \\
\text { pos. (2) } \\
\text { pos. (4) }\end{array}$ & $\begin{array}{c}\text { Diff. bet. } \\
\text { test and } \\
\text { calc. } \\
\text { pos. } 2\end{array}$ & $\begin{array}{l}\text { same as } \\
\% \text { of pos. } \\
\text { (2) temp. } \\
\text { rise }\end{array}$ \\
\hline Long & Yes & 150 & 20 & 20 & 20 & 70 & 1.0 & 117 & 115 & 117 & 116 & 20 & 18 & -2 & 1.7 \\
\hline a & " & 200 & " & “ & 20 & 53 & ". & 98 & 96 & 98 & $\begin{array}{r}96 \\
96\end{array}$ & 20 & 18 & -2 & 2.1 \\
\hline “ & “ & 300 & " & “ & 20 & 37 & “ & 80 & 78 & 80 & 78 & 20 & 18 & -2 & 2.6 \\
\hline “ & “ & 600 & “ & $"$ & 20 & 22 & “ & 63 & 61 & 63 & 61 & 20 & 18 & -2 & $\mathbf{3 . 3}$ \\
\hline " & " & 900 & “ & " & 20 & 16.5 & " & 54.5 & 53.5 & 54.5 & 53.5 & 20 & 19 & -1 & 1.9 \\
\hline " & “ & 1400 & " & " & 20 & 10.5 & $"$ & 44.5 & 43.5 & 44.5 & 43.5 & 20 & 19 & -1 & 2.3 \\
\hline “ & “ & 300 & 25 & 20 & 20 & 52.5 & 1.56 & 122 & 128.5 & 97 & 96.5 & 32.5 & 39 & +6.5 & -5.1 \\
\hline “ & " & 1400 & 20 & 20 & 20 & 11.0 & 1.0 & 47 & 45 & 47 & 47 & 20 & 18 & -2 & 4.4 \\
\hline “ & “ & 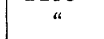 & 25 & 20 & 20 & 17.0 & 1.56 & 67 & 71 & 49 & 49 & 29 & 33 & +4 & -5.6 \\
\hline " & “ & " & 28 & 20 & 20 & 20.0 & 1.96 & 82.5 & 90 & 52 & 53 & 35.5 & 43 & $\begin{array}{r}7.5 \\
+7.5\end{array}$ & -8.3 \\
\hline “ & No & 1400 & 20 & 20 & 6 & 11.0 & 1.00 & 46 & 47 & 46 & 49 & 6 & 7 & +1 & -2.12 \\
\hline “ & $"$ & " & 25 & 20 & 6 & 14.5 & 1.56 & 72 & 71.5 & 51.2 & 54.5 & 16.5 & 16.0 & -5 & .7 \\
\hline “ & " & " & 27.5 & 20 & 6 & 19 & 1.89 & 92.4 & 91.0 & 57.8 & 61 & 23.4 & 22 & -1.4 & 1.5 \\
\hline " & “ & 300 & 20 & 20 & 6 & 45.5 & 1.00 & 92.5 & 91.5 & 92.5 & 92.5 & 6 & 5 & -1.0 & 1.1 \\
\hline “ & “ & " & 24.7 & 19.4 & 6 & 60.5 & 1.62 & 140 & 133.5 & 109 & 109.5 & 21.5 & 15 & -6.5 & 4.9 \\
\hline “ & “ & “ & 27.5 & 19.6 & 6 & 70.5 & 1.97 & 170 & 164.5 & 12.1 & 124.5 & 30.5 & 25 & -5.5 & 3.3 \\
\hline * & " & 600 & 20 & 20 & 6 & 28. & 1.00 & 69. & 68. & 69. & 71.5 & 6. & 5 & -1.0 & 1.4 \\
\hline - & “ & " & 25 & “ & 6 & 30.5 & 1.56 & 102.5 & 97.5 & 76.8 & 78.5 & 19. & 14 & -5.0 & 5.1 \\
\hline " & " & “ & 27.5 & “ & 6 & 40.5 & 1.89 & 132. & 125.5 & 89.2 & 91.5 & 27.5 & 21 & -6.5 & 5.2 \\
\hline Short & Yes & 150 & 20 & 20 & 13 & 40 & 1.00 & 72 & 70 & 72 & 73 & 13 & 11 & -2 & 2.9 \\
\hline & “ & 230 & “ & “ & 13 & 30 & 1.00 & 60 & 58 & 60 & 62 & 13 & 11 & -2 & 3.5 \\
\hline “ & “ & 310 & " & " & 13 & 24 & 1.00 & 54 & 51 & 54 & 54 & 13 & 10 & -1 & 2.0 \\
\hline “ & “ & 400 & “ & " & 13 & 20 & 1.00 & 49 & 46 & 49 & 49 & 13 & 10 & -1 & 2.2 \\
\hline “ & “ & 600 & " & $"$ & 13 & 15 & 1.00 & 44 & 41 & 44 & 44 & 13 & 10 & -1 & 2.4 \\
\hline " & “ & 1400 & " & “ & 13 & 9 & 1.00 & 35.0 & 35 & 35.0 & 37 & 13 & 13.0 & 0.0 & 00.0 \\
\hline " & " & " & 25 & “ & 13 & 13 & 1.56 & 50.7 & 55 & 37.3 & 38 & 19.7 & 24 & +4.3 & -7.8 \\
\hline “ & “ & “ & 24.5 & 20.8 & 13 & 11.5 & 1.50 & 51.2 & 53.5 & 37.9 & 38.5 & 19.7 & 22 & +2.3 & -4.3 \\
\hline “ & “ & “ & 27.5 & 20.0 & 13 & 13.0 & 1.90 & 60.0 & 65.0 & 38.0 & 39.0 & 24 & 29 & +5 & -7.7 \\
\hline
\end{tabular}

The difference between the upper and lower coil temperatures is

TABLE II

COMPARISON OF CALCULATED AND TEST RESULTS-ARMATURE MODEL

coil is the $I^{2} R$ loss plus the eddy current loss, both of which can be calculated in a given case. ${ }^{1}$ Let this 1 See Eddy Current Losses in Armature Conductors. R. E. Gilman, A. I. E. E. Transactions 1920; also article by S. L. Henderson, Electric Journal, September 1920, giving prinoipal formulas with examples.

$$
\left(\theta_{t}-\theta_{b}\right)=\frac{2\left(\theta_{m}+\theta_{a}-\theta_{i}\right)(L . R .-1)}{L . R .+1}
$$

Equation (4) then gives the top coil temperature rise, and equation (6) gives the conventional allowance. 
It remains to establish the variation of $\theta_{a}$ with core length, insulation thickness and rate of heat flow. This can be done from the results of the model tests and the

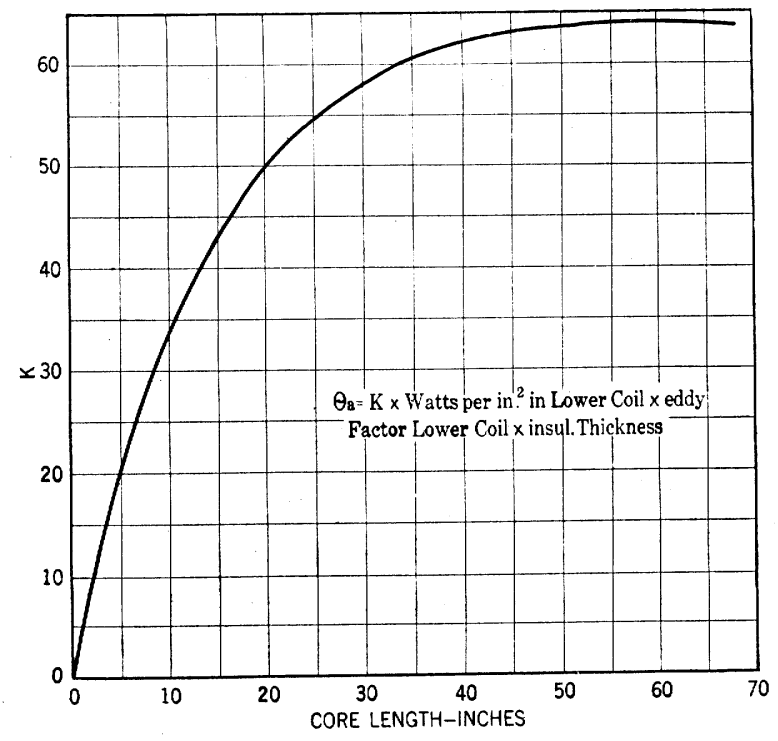

FIg. 9

generator tests described later. It will be noted that the following values were obtained for the conditions tested and were used in obtaining the calculated values given in Table II.

For 13,200-volt insulation and very long core

(say in excess of 60 inches)......20 deg.
For 13,200-volt insulation and very short cores

(8 $1 / 2$ inches)..............13 deg

For 6600 -volt insulation and very long core... $6 \mathrm{deg}$.

The value $\theta_{a}$ remains constant with varying loss ratios, varying core temperatures and with constant loss in the bottom coil as shown by the model tests.

No tests were made with varying loss in the bottom coil but a little consideration will show that the heat flow to the slot sides (and consequently the. value of $\theta_{a}$ ) will vary in proportion to the rate of heat flow from the bottom coil (or the watts per square inch of coil surface).

It is also assumed (from the fundamentals of heat flow) that $\theta_{a}$ is proportional to the insulation thickness. We may then write $\theta_{a}=K \times$ watts per sq. in. $\times$ insulation thickness

In this expression $K$ varies with core length. In long core machines (say over 60 inches) the heat generated in the copper at the center of the core is transmitted wholly across the insulation wall to the core. As the core length diminishes a greater part of the heat generated in the copper at the center of the core is transmitted along the copper to the external coil ends and the part transmitted across the insulation wall diminishes. The effect of variation in core length, therefore, is to vary the watts per square inch transmitted across the insulation wall. The relations between core length and division of heat flow between

TABLE III

\begin{tabular}{|c|c|c|c|c|c|c|c|c|c|c|c|c|c|c|c|c|c|c|c|c|c|c|}
\hline \multirow[b]{2}{*}{ 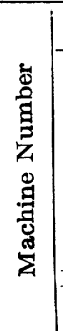 } & \multicolumn{5}{|c|}{ Rating } & \multirow[b]{2}{*}{$\begin{array}{l}\frac{1}{10} \\
00 \\
0 \\
0 \\
0 \\
0 \\
0 \\
0\end{array}$} & \multirow[b]{2}{*}{ 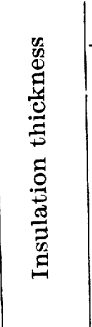 } & \multicolumn{3}{|c|}{ Test Conditions } & \multicolumn{6}{|c|}{ Data under Test Conditions } & \multicolumn{5}{|c|}{ Maximum Temperature Rise } & \multirow[b]{2}{*}{ 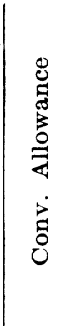 } \\
\hline & K. V. & 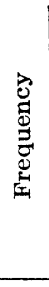 & Volts & Amp & R. P. & & & Volts & Amp. & 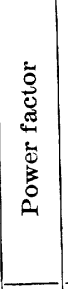 & 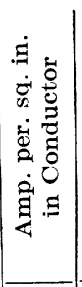 & 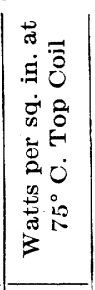 & 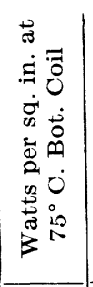 & 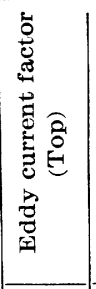 & 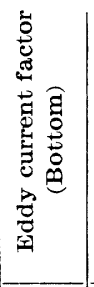 & $\begin{array}{l}\text { Loss } \\
\text { Ratio }\end{array}$ & 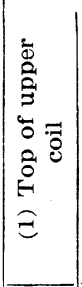 & 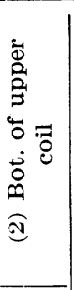 & 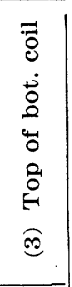 & 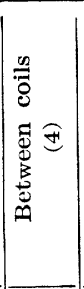 & 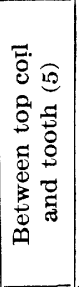 & \\
\hline 1 & 1 & 60 & 2300 & 313 & 00 & 14 & 125 & 2300 & 313 & 0 & 410 & 1.02 & 1.00 & .02 & 1.004 & 1.016 & 46.6 & 52.7 & & 51.4 & 44.5 & 1.3 \\
\hline 2 & 1250 & 60 & 2400 & 300 & 3600 & 33.5 & 0.138 & & & 0 & 2170 & 584 & 0.564 & & 1.07 & 1.03 & & 53.0 & 48.5 & 48.2 & 37.0 & 4.8 \\
\hline 3 & & & & & & & & 2400 & 38 & 0 & 2770 & 0.950 & 0.920 & 1.106 & 1.07 & 1.04 & & 73.5 & 67 & & $\begin{array}{l}44.0 \\
32.5\end{array}$ & 5.5 \\
\hline 4 & $\begin{array}{l}1560 \\
3000\end{array}$ & $\begin{array}{l}60 \\
25\end{array}$ & $\begin{array}{l}2200 \\
2300\end{array}$ & $\begin{array}{l}410 \\
750\end{array}$ & $\begin{array}{r}36 \\
7\end{array}$ & 46 & .162 & $\begin{array}{l}2000 \\
2300\end{array}$ & 45 & 0 & $\begin{array}{l}1820 \\
1860\end{array}$ & $\begin{array}{l}0.455 \\
0.400\end{array}$ & $\begin{array}{l}0.391 \\
0.392\end{array}$ & $\begin{array}{l}1.215 \\
1.02\end{array}$ & $\begin{array}{l}1.04 \\
1.004\end{array}$ & $\begin{array}{l}1.16 \\
1.015\end{array}$ & $\begin{array}{l}68.3 \\
30\end{array}$ & $\begin{array}{l}58.9 \\
32.3\end{array}$ & & $\begin{array}{l}46.2 \\
32.3\end{array}$ & $\begin{array}{l}32.5 \\
25.4\end{array}$ & $\mid \begin{array}{c}12.7^{*} \\
0.0\end{array}$ \\
\hline & & & & & & & & & $\begin{array}{l}54 \\
75\end{array}$ & $\begin{array}{l}0 \\
0\end{array}$ & 2580 & 0.764 & 0.750 & 1.02 & 1.004 & 1.015 & 41.5 & 45 . & & 45.5 & 32.5 & 0.0 \\
\hline 5 & 3125 & 62 & 2300 & 785 & 750 & 25 & 0.115 & 2300 & 559 & 0 & 1890 & 0.5 & 0.4 & 1.215 & 1.084 & 1.12 & 45 & 48.5 & & 48.5 & 41.0 & 0.0 \\
\hline & & & & & & & & 1940 & 785 & 0 & 2660 & 0. & 0.8 & 15 & 1.084 & 1.12 & 59.5 & 65.0 & & 64.0 & & 1.0 \\
\hline 6 & 750 & 60 & 6600 & 65.6 & 300 & 14.5 & 0.131 & 6600 & 58.3 & 0 & 2200 & 0.577 & 0.562 & 1.0 & 1.0 & 1.025 & 35 & 36 & & 34 & & 2.0 \\
\hline 7 & 1250 & 25 & & 113 & 300 & 13 & 0.182 & 00 & 113 & 0 & 2460 & 0.766 & 0.7 & 008 & 1. & 1.008 & 55.8 & 61.3 & & 59.4 & 40.8 & 1.9 \\
\hline 8 & 2450 & 25 & 000 & 214 & 750 & 25 & .175 & 00 & 18 & 0 & 2090 & 0.533 & 0.5 & 26 & 1. & 1.009 & 33 & 35 & & & 25 & 6.0 \\
\hline 9 & 2500 & 60 & 6600 & 219 & 240 & 1 & 17 & 6600 & 21 & $\mathbf{0}$ & 2670 & 1.71 & 1.2 & 1.4 & 1.0 & 1.37 & 78.5 & 75 & 74 & & 62.5 & 3.0 \\
\hline 10 & 5500 & 60 & 6600 & 481 & 225 & 22.5 & 0.144 & 6600 & 48 & 0 & 1970 & 0.790 & 0 . & & 1.0 & 1.2 & 77.5 & 68.5 & 65 & 63.5 & 60.5 & 5.0 \\
\hline 11 & 00 & 60 & 600 & 525 & 600 & 21.5 & 0.142 & 6600 & 52 & 0 & 2510 & 278 & & & 1.0 & 1.26 & 83.8 & 82.5 & 79.5 & 72.1 & 61.9 & 10.4 \\
\hline 12 & 12000 & 60 & 00 & 1050 & 150 & 33 & 0.165 & 6600 & 960 & 0 & 1820 & 0.821 & 0.645 & 1.58 & 1. 2 & 1.27 & 78.3 & 72.6 & & 64 & 54 & 8.6 \\
\hline 13 & 2500 & 50 & 11000 & 131 & 750 & 15 & 0.24 & 0 & 131 & $\begin{array}{l}\text { s. c. } \\
\text { unde }\end{array}$ & $\begin{array}{l}2245 \\
\text { r exc. }\end{array}$ & 0.62 & 0.595 & 1.061 & 1.02 & 1.04 & 38.4 & & & 29.8 & 28.0 & 8.6 \\
\hline & & & & & & & & 11000 & 131 & 0 & 2300 & 0.814 & 0.756 & 1.186 & 1.026 & 1.15 & 68 & 76 & & 66 & & 10.0 \\
\hline 14 & 2500 & 50 & 11000 & 131 & 750 & 16 & 0.211 & 11000 & 131 & $\begin{array}{r}\text { over } \\
0\end{array}$ & $\left|\begin{array}{l}\text { exc. } \\
2300\end{array}\right|$ & 0.874 & 0.756 & 1. 186 & 1.026 & 1.15 & & 95 & & 88 & & 7.0 \\
\hline 15 & 1250 & 50 & 15000 & 48 & 750 & 20 & & 15000 & 48 & .90 & & & & & & & 32 & 33 & 52 & & 26.5 & 5.0 \\
\hline & & & 000 & & & & & & $\begin{array}{r}72 \\
250\end{array}$ & $\begin{array}{r}.95 \\
0\end{array}$ & & & & & & & $\begin{array}{l}51.5 \\
56.5\end{array}$ & $\begin{array}{l}52.5 \\
61 \dagger\end{array}$ & & & $\left|\begin{array}{l}37.0 \\
43\end{array}\right|$ & $\left|\begin{array}{l}11.0 \\
12.5\end{array}\right|$ \\
\hline
\end{tabular}

In machines 1-4-5-7-8-13-15-16-10-inch resistance detectors are used; those inside main insulation are in contact with cotton covering of wires; or machines have thermocouples and couples inside insulation are in contact with bare copper. All detectors are located in center of core, lengthwise. 
the transverse and longitudinal paths are quite complicated, but these have been investigated and the general shape of the curve is known. ${ }^{2}$

The curve, Fig. 9, showing the relation between $K$ and core length has been arrived at from a consideration of these general relations, and the experimental data from both the model tests and the tests on machines. The data from the model tests with extra insulation between coils have not been used (except as an indication of the relative variation of $K$ with core length) because of the known fact that the heat conductivity of laminated insulation varies greatly with and across the laminations. ${ }^{3}$ With the extra insulation between coils as used in the model, the layers of the insulation were not rounded, as would be the case with coil insulation, but lay flat. See Fig. 3. Consequently the side flow of heat was greater and the temperature drop was greater than in the usual case. of the A. I. E. E. arranged to make tests on generators of three different manufacturers to obtain data that would be useful in the revision of the temperature limits of large machines using the embedded temperature detector method of measurement.

Tests were made on sixteen generators ranging in size from $750 \mathrm{kv}$-a. to $12,000 \mathrm{kv}$-a. at various voltages from 2300 volts to 15,000 volts and speeds from 150 rev. per min. to $3600 \mathrm{rev}$. per min. Very large turbine type generators were not included in this program, because another series of tests on such machines had previously been arranged.

The tests conducted by the subcommittee were made in the testing departments of the several manufacturing companies. Each test was supervised by the member of the subcommittee located at the plant. In all of the machines detectors were built into the armature coils to measure the temperature of the copper of the

TABLE IV

\begin{tabular}{|c|c|c|c|c|c|c|c|c|c|c|c|c|c|c|}
\hline $\begin{array}{c}\text { Machine } \\
\text { No. }\end{array}$ & $\begin{array}{c}\text { Core } \\
\text { length }\end{array}$ & $\begin{array}{l}\text { Value } \\
\text { of } K\end{array}$ & $\begin{array}{c}\text { Insula- } \\
\text { tion } \\
\text { thickness }\end{array}$ & $\begin{array}{c}\text { Watts } \\
\text { per sq. in } \\
\text { bottom }\end{array}$ & $\begin{array}{c}\text { Calc. } \\
\text { value } \theta_{a}\end{array}$ & $\begin{array}{l}\text { Loss } \\
\text { ratio }\end{array}$ & $\theta_{m}$ & $\theta_{i}$ & $\begin{array}{c}\text { Calc. . } \\
\text { value } \theta i\end{array}$ & $\begin{array}{c}\text { Tested } \\
\text { value } \theta t\end{array}$ & $\begin{array}{c}\text { Calc. } \\
\text { value } \\
\text { conven- } \\
\text { tional all. }\end{array}$ & $\begin{array}{c}\text { Tested } \\
\text { value } \\
\text { conven- } \\
\text { tional all. }\end{array}$ & {$\left[\begin{array}{c}\theta \text { (test) } \\
-\theta t \\
(\text { calc. })] \\
\times 100 \\
\theta t \text { (test) }\end{array}\right.$} & \\
\hline 1 & 14 & 42 & 0.125 & 1.00 & 5.25 & 1.016 & 51.4 & 44.5 & 56.8 & 52.7 & 5.4 & 1.3 & -7.8 & \\
\hline \multirow[t]{2}{*}{2} & 33.5 & 60 & 0.138 & 0.564 & 4.65 & 1.03 & 48.2 & 37 & 53.2 & 53 & 5.0 & 4.8 & $-\quad .38$ & \\
\hline & & & & 0.920 & 7.65 & 1.03 & 68.0 & 44 & 76.3 & 73.5 & 8.3 & 5.5 & $-\quad 3.8$ & \\
\hline $\mathbf{3}$ & 46 & 63 & 0.162 & 0.391 & 4.00 & 1.16 & 46.2 & 32.5 & 51.6 & 58.9 & 5.4 & $12.7 *$ & +14.2 & \\
\hline \multirow[t]{2}{*}{4} & 33 & 59.5 & 0.125 & 0.392 & 2.90 & 1.015 & 32.3 & 25.4 & 35.3 & 32.3 & 3.0 & 0.0 & -9.3 & \\
\hline & & & & 0.750 & 5.50 & 1.015 & 45.5 & 32.5 & 51.3 & 45.5 & 5.8 & 0.0 & -12.7 & \\
\hline \multirow[t]{2}{*}{5} & 25 & 54.5 & 0.115 & 0.449 & 2.82 & 1.12 & 48.5 & 41.0 & 51.9 & 48.5 & 3.4 & 0.0 & $-\quad 7.0$ & \\
\hline & & & & 0.886 & 5.60 & 1.12 & 64.0 & $54 \dagger$ & 70.5 & 65.0 & 6.5 & 1.0 & 8.5 & \\
\hline 6 & 14.5 & 43 & 0.131 & 0.562 & 3.18 & 1.025 & 34 & $33 \dagger$ & 37.9 & 36.0 & 3.9 & 2.0 & 4.5 & \\
\hline 7 & 13 & 39 & 0.182 & 0.760 & 5.40 & 1.008 & 59.4 & 40.8 & 64.8 & 61.3 & 5.4 & 1.9 & 5.4 & \\
\hline 8 & 25 & 54 & 0.175 & 0.527 & 5.0 & 1.009 & 29 & 25 & 34 & 35 & 5 & 6 & 2.85 & \\
\hline 9 & 13 & 39 & 0.117 & 1.25 & 5.72 & 1.37 & 72 & 62.5 & 80 & 75 & 8.0 & 3.0 & 6.25 & \\
\hline 10 & 22.5 & 52 & 0.144 & 0.63 & 4.7 & 1.25 & 63.5 & 60.5 & 69.1 & 68.5 & 5.6 & 5.0 & 8.7 & \\
\hline 11 & 21.5 & 50 & 0.142 & 0.63 & 7.2 & 1.26 & 72.1 & 61.9 & 81.4 & 82.5 & 9.3 & 10.4 & 1.09 & \\
\hline 12 & 33 & 60 & 0.165 & 0.645 & 6.5 & 1.27 & 64.0 & 54.0 & 72.5 & 72.6 & 8.5 & 8.6 & 1.3 & \\
\hline 13 & 15 & 43 & 0.24 & 0.595 & 6.25 & 1.04 & 29.8 & 28 & 36.3 & $38.4 \ddagger$ & 6.5 & 8.6 & 6.0 & \\
\hline \multirow[t]{2}{*}{14} & 16 & 44 & 0.211 & 0.756 & 7.0 & 1.15 & 66 & $58 \dagger$ & 74.4 & 76 & 8.4 & 10 & 2.1 & under exc. \\
\hline & & & & 0.756 & 7.0 & 1.15 & 88 & $70 \dagger$ & 96.8 & 95 & 8.8 & 7 & $+\quad 1.87$ & over exc. \\
\hline
\end{tabular}

*Temperature affected by flux from field augmenting loss. Iron temperature at bottom of slot.

$\dagger$ Iron temperature assumed, not given from test.

$\ddagger$ On copper of top of upper coil.

Note: Iron temp. not given from tests: The iron temperature rises by thermometer were increased by amounts indicated by tests on other machines. The iron temperature, as used in formula, has small influence upon the copper temperature, except when the loss ratio is high.

In equation (8) the watts per square inch refer to the bottom coil, the watts being the $I^{2} R$ loss at 75 deg. cent., plus the calculated eddy current loss in the bottom coil at the same temperature, and the surface being that of the bare copper, omitting the side adjacent to the top coil. The insulation thickness is taken as one-half the difference between slot width and bare copper width.

\section{Generator Tests}

At a meeting held November 4, 1920, the Rotating Machinery Subcommittee of the Standard Committee

2. Longitudinal and Transverse Heat Flow in Slot-Wound Armature Coils. C. J. Fechheimer, Journal, A. I. E. E., March, April and May 1921.

3. The Thermal Conductivity of Insulating and other Materials, T. S. Taylor, Electric Journal, December, 1919. top coil and detectors were located between coil sides. In some of the machines detectors were also located inside the insulation of the bottom coil and between the top coil and core tooth.

The essential design information and test results are given in Table III.

A word of caution may be required against using these generator tests directly for estimating probable or reasonable limiting values of conventional allowance or measureable temperature rise. The generators selected for test were, in six cases, of shorter core length than the limit set in the Rules for the detector method of measurement; in five cases were for low voltage; in three cases were for low frequency; and in general were of such size and characteristics that low rises and values of conventional allowance should be expected. 
The entire class of large turbo generators was intentionally excluded. But while these tests may not be used directly for determining probable limiting values, they are as good as any for the purpose employed in this paper; viz., for checking the validity of the method of calculation that is developed from the model tests.

The formulas derived from the results of the model tests have been verified by checking values of the top coil temperature and conventional allowance calculated by them against the measured values of the machines tested. The results of this comparison are shown in Table IV. This agreement is sufficiently close to warrant the statement that the conventional allowance can be calculated with a fair degree of accuracy for any machine when the following data are available:

1. Observed temperature rise by detector between coil sides.

2. Observed temperature rise of tooth by detector at side or bottom of slot.

3. Ratio of copper loss to coil surface. (Watts per square inch.)

4. Eddy current losses (loss ratio).

5. Thickness of insulation.

6. Length of core.

As might be expected, some of the test results do not check with the calculated results as closely as others.

The two units No. 4 and No. 5 show practically no difference between the copper temperature and observable temperature. These two machines are among those having ten-inch detectors inside the main coil insulation (in contact with the cotton covering on the wires) instead of thermocouples in contact with the bare copper. With thin insulation (for 2300 volts) low loss ratios and low temperature rise, the conventional allowance will be naturally low and the method of measuring the copper temperature will have a relatively large influence on the measured difference between the copper and observable temperatures.

Unit No. 3 shows a higher measured conventional allowance than can be accounted for. This is a twopole turbo-generator and the designer explains this discrepancy by the existence of extra losses in the top coil caused by the penetration of main rotor flux into the slot.

As will be evident by considering the method of derivation, the formula for calculating the top coil temperature gives the temperature of that part of the top coil adjacent to the bottom coil. (Position 2, Table III). In generators having small eddy current losses, this is the maximum temperature of the top coil; in generators having larger eddy current losses or in which the main field flux penetrates the slots, thus producing additional eddy current losses, the temperature of that part of the top coil adjacent to the air gap (Position 1, Table III) is the maximum. This is illustrated by the following figures taken from Table III.

\begin{tabular}{|c|c|c|c|c|}
\hline Unit No. & L. R. & $\begin{array}{l}\text { Position } 1 \\
\text { top of } \\
\text { upper coil }\end{array}$ & $\begin{array}{l}\text { Position } 2 \\
\text { bottom of } \\
\text { upper coil }\end{array}$ & Diff. \\
\hline 3 & 1.16 & 68.3 & 58.9 & 9.4 \\
\hline 9 & 1.37 & 78.5 & & 3.5 \\
\hline 10 & 1.25 & 77.5 & 68.5 & 9.0 \\
\hline 11 & 1.26 & 83.8 & 82.5 & 1.3 \\
\hline 12 & 1.27 & 78.3 & 72.6 & 5.7 \\
\hline
\end{tabular}

In the comparison between measured and calculated top coil temperatures, the test values given in Table IV are for Position 2 in every case, and this fact should be considered in drawing any conclusions as to the probable range of values of conventional allowance in practise.

\section{Calculation of the Conventional allowance FOR LIMITING CASES}

The only values of the conventional allowance that are of interest from the standpoint of standardization are those that exist at the limiting copper temperatures. In determining the proper value of the conventional allowance for the temperature limit of Class $A$ insulation, for example, the values of the conventional allowance that exist when the copper temperature is 105

\section{TABLE V}

CALCULATED CONVENTIONAL ALLOWANCES 6600-Volt Insulation-105 deg. Copper Temperature. Insulation Thickness- 0.15 inch Calculations are based on long core machines.

\begin{tabular}{|c|c|c|c|c|c|c|c|c|c|}
\hline $\begin{array}{c}\text { Top coil temp. } \\
\text { rise } \ldots \ldots \ldots \ldots\end{array}$ & 65 & 65 & 65 & 65 & 65 & 65 & 65 & 65 & 65 \\
\hline Core temp.rise.. & 25 & 35 & 45 & 25 & 35 & 45 & 25 & 35 & 45 \\
\hline $\begin{array}{c}\text { Temp. drop } \\
\text { through ins... }\end{array}$ & 40 & 30 & 20 & 40 & 30 & 20 & 40 & 30 & 20 \\
\hline $\begin{array}{l}\text { Watts per sq. in., } \\
\text { top.......... }\end{array}$ & 0.8 & 0.6 & 0.4 & 0.8 & 0.6 & 0.4 & 0.8 & 0.6 & 0.4 \\
\hline Loss ratio...... & 1. 10 & 1.10 & 1.10 & 1.20 & 1.20 & 1. 20 & 1.40 & 1.40 & 1.40 \\
\hline $\begin{array}{r}\text { Watts per sq. in., } \\
\text { bot........... }\end{array}$ & 0.73 & 0.54 & 0.36 & 0.67 & 0.50 & 0.33 & 0.57 & 0.43 & 0.28 \\
\hline$\theta_{a} \ldots \ldots \ldots \ldots$ & 7 & 5.2 & 3.5 & 6.5 & 4.8 & 3.2 & 5.5 & 4.1 & 2.7 \\
\hline$\theta_{m} \ldots \ldots \ldots \ldots$ & 56.2 & 58.4 & 60.6 & 55.1 & 57.7 & 60.1 & 53.8 & 56.6 & 59.4 \\
\hline $\begin{array}{l}\text { Conventional } \\
\text { allowance.... }\end{array}$ & 8.8 & 6.6 & 4.4 & 9.9 & 7.3 & 4.9 & 11.2 & 8.4 & 5.6 \\
\hline
\end{tabular}

deg. are the only ones that are of interest. It is possible, then, to assume various sets of conditions (all of which result in 105 deg. copper temperature) and to calculate the conventional allowance, and, in that way, obtain a quantitative idea of the range of values of the conventional allowance at the assumed limiting copper temperature.

TABLE VI

CALCULATED CONVENTIONAL ALLOWANCES. 13200-Volt Insulation-105 deg. Copper Temperature. Insulation Thickness- 0.25 inch

Calculations are based on long core machines.

\begin{tabular}{|c|c|c|c|c|c|c|c|c|c|}
\hline $\begin{array}{c}\text { Top coil temp. } \\
\text { rise } \ldots \ldots \ldots \ldots\end{array}$ & 65 & 65 & 65 & 65 & 65 & 65 & 65 & 65 & 65 \\
\hline Core temp. rise. & 25 & 35 & 45 & 25 & 35 & 45 & 25 & 35 & 45 \\
\hline $\begin{array}{c}\mathrm{T} \text { e m p. d rop } \\
\text { through ins. }\end{array}$ & 40 & 30 & 20 & 40 & 30 & 20 & 40 & 30 & 20 \\
\hline $\begin{array}{l}\text { Watts per sq. } \\
\text { in., top...... }\end{array}$ & 0.48 & 0.36 & 0.24 & 0.48 & 0.36 & 0.24 & 0.48 & 0.36 & 0.24 \\
\hline Loss ratio. . . . . & 1.10 & 1.10 & 1.10 & 1.20 & 1.20 & 1.20 & 1.40 & 1.40 & 1.40 \\
\hline $\begin{array}{r}\text { Watts per sq. } \\
\text { in.,bot...... }\end{array}$ & $0 . \dot{435}$ & 0.33 & 0.22 & 0.40 & 0.30 & 0.20 & 0.34 & 0.26 & 0.17 \\
\hline$\theta_{a} \ldots \ldots \ldots \ldots$ & 7.0 & 5.2 & 3.5 & 6.5 & 4.8 & 3.2 & 5.5 & 4.1 & 2.7 \\
\hline$\theta_{m} \ldots \ldots \ldots \ldots$ & 56.2 & 58.4 & 60.6 & 55.1 & 57.7 & 60.1 & 53.8 & 56.6 & 59.4 \\
\hline $\begin{array}{c}\text { Conventional } \\
\text { allowance... }\end{array}$ & 8.8 & 6.6 & 4.4 & 9.9 & 7.3 & 4.9 & 11.2 & 8.4 & 5.6 \\
\hline
\end{tabular}


Tables V and VI show such calculated values of the conventional allowance for $105 \mathrm{deg}$. total copper temperature and for insulation thickness corresponding to 6600 volts and 13,200 volts. The figures in each table cover a reasonable range in core temperature and in loss ratio (eddy current factors) to fairly represent current design practise.

In Tables V and VI, the values of core temperature and loss ratio are arbitrarily taken so as to cover the range of current design practise. The temperature of the top coil $\left(\theta_{t}\right)$ follows from $105 \mathrm{deg}$. minus $40 \mathrm{deg}$. air temperature. The temperature drop through the insulation is then $65 \mathrm{deg}$. minus the core temperature. Knowing this temperature drop, the watts per square inch follows from the thickness of insulation and heat conductivity of the insulation. (This is assumed as 0.003 watts per inch cube per degree). Dividing the watts per square inch of the top coil by the loss ratio gives the watts per square inch of the bottom coil. The constant $K$ and $\theta_{a}$ and the observable temperature rise $\theta_{m}$ can then be calculated and the conventional allowance obviously follows. The measureable temperature rise $\left(\theta_{m}\right)$ is calculated from equation $(9)$ which is merely a transposed form of equation (4):

$$
\theta_{m}=\frac{\theta_{t}+\theta_{i}}{2}+\frac{\theta_{t}-\theta_{i}}{2 L R}-\theta_{a}
$$

These calculated values are based on long machines, say sixty inches and longer. A little consideration will show that, for a given copper temperature, the conventional allowance is practically the same for all core lengths. Generators, as ordinarily designed have the same current density and ratio of loss to coil surface for a considerable range of core lengths. This results in shorter-core machines having lower copper temperatures and smaller conventional allowances, as a rule, than longer-core machines. But, if machines of short core length were designed with higher current densities and smaller cooling surfaces so as to have the same limiting copper temperature as long-core machines, the conventional allowances would be substantially the same. Therefore, for the purpose of establishing reasonable values of conventional allowance, core length need not be considered.

It will be observed from a comparison of corresponding columns in Tables V and VI that while the watts
TABLE VII

CALCULATED CONVENTIONAL ALLOWANCES. 13200-Volt Insulation-125 deg. Copper Temperature. Insulation Thickness- 0.25 inch

Calculations are based on long core machines.

\begin{tabular}{|c|c|c|c|c|c|c|c|c|c|}
\hline $\begin{array}{l}\text { Top coil temp. } \\
\text { rise } \ldots \ldots \ldots \ldots\end{array}$ & 85 & 85 & 85 & 85 & 85 & 85 & 85 & 85 & 85 \\
\hline Core temp. rise. & 30 & 40 & 50 & 30 & 40 & 50 & 30 & 40 & 50 \\
\hline $\begin{array}{c}\text { Te m p. rise } \\
\text { through ins.. }\end{array}$ & 55 & 45 & 35 & 55 & 45 & 35 & 55 & 45 & 35 \\
\hline $\begin{array}{r}\text { Watts per sq. } \\
\text { in., top...... }\end{array}$ & 0.66 & 0.54 & 0.42 & 0.66 & 0.54 & 0.42 & 0.66 & 0.54 & 0.42 \\
\hline Loss ratio..... . & 1.10 & 1.10 & 1.10 & 1.20 & 1.20 & 1.20 & 1.40 & 1.40 & 1.40 \\
\hline $\begin{array}{l}\text { Watts per sq. } \\
\text { in., bot....... }\end{array}$ & 0.60 & 0.49 & 0.38 & 0.55 & 0.45 & 0.35 & 0.47 & 0.385 & 0.30 \\
\hline$\theta_{a} \ldots \ldots \ldots \ldots$ & 9.6 & 7.9 & 6.1 & 8.8 & 7.2 & 5.6 & 7.6 & 6.1 & 4.8 \\
\hline $\begin{array}{l}\theta_{m} \ldots \ldots \ldots \ldots \\
\text { Conventional }\end{array}$ & 72.9 & 75.1 & 77.2 & 71.7 & 74.1 & 76.5 & 69.5 & 72.3 & 75.2 \\
\hline allowance.... & 12.1 & 9.9 & 7.8 & 13.3 & 10.9 & 8.5 & 15.5 & 13.7 & 9.8 \\
\hline
\end{tabular}

per square inch for 6600 and 13,200 volts are different, the values of $\theta_{a}, \theta_{m}$ and conventional allowance are identical. In other words, the conventional allowance with given copper temperature, core temperature and loss ratio, is independent of insulation thickness. For purposes of standardization, therefore, no distinction need be made between low-voltage and high-voltage generators, within the range of generator sizes for which the detector method is specified. The reason for this will be evident from equation (9). The only term

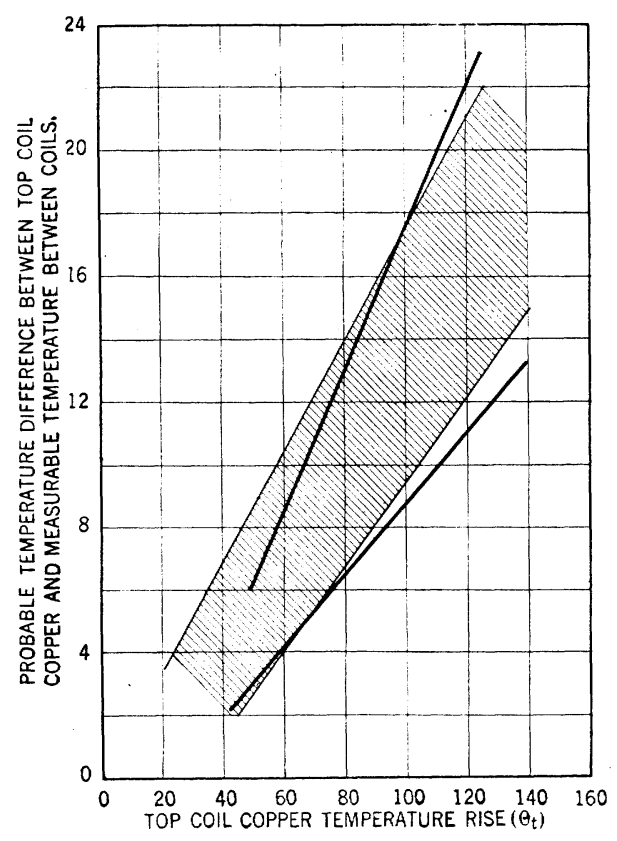

FIG. 10

TABLE VIII.

CALCULATED CONVENTIONAL ALLOWANCES. 13200-Volt Insulation-150 deg. Copper Temperature. Insulation Thickness- 0.25 inch

Calculations are based on long core machines.

\begin{tabular}{|c|c|c|c|c|c|c|c|c|c|}
\hline Top coil temp. rise $\left(\theta_{t}\right) \ldots \ldots \ldots$ & 110 & 110 & 110 & 110 & 110 & 110 & 110 & 110 & 110 \\
\hline Core temp. rise ( $g_{i}$ ) (assumed)... & 40 & 50 & 60 & 40 & 50 & 60 & 40 & 50 & 60 \\
\hline Temp. drop through insulation. . . & 70 & 60 & 50 & 70 & 60 & 50 & 70 & 60 & 50 \\
\hline Watts per sq. in. (top coil) ...... & 0.84 & 0.72 & 0.60 & 0.84 & 0.72 & 0.60 & 0.84 & 0.72 & 0.60 \\
\hline Loss ratios (assumed) . . . . . & 1.10 & 1. 10 & 1.10 & 1.20 & 1.20 & 1.20 & 1.40 & 1.40 & 1.40 \\
\hline Watts per sq. in. (bot. coil).. & 0.76 & 0.64 & 0.55 & 0.70 & 0.60 & 0.50 & 0.60 & 0.51 & 0.43 \\
\hline 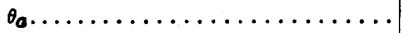 & 12.2 & 10.2 & 8.9 & 11.2 & 9.6 & 8 & 9.6 & 8 & 6.9 \\
\hline 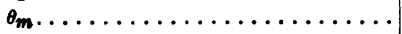 & 94.8 & 96.8 & 98.8 & 92.8 & 96.4 & 97.9 & 90.4 & 94.0 & 95.9 \\
\hline Conventional allowance........ & 15.2 & 14.2 & 11 & 17.2 & 13.6 & 12.1 & 19.6 & 16.0 & 14.1 \\
\hline
\end{tabular}


in this equation affected by insulation thickness is $\theta_{a}$. This term, it will be remembered, is

$\theta_{a}=K \times$ watts per sq. in. $\times$ insulation thickness

But, for constant copper temperature, the product of watts per square inch and insulation thickness is constant, and therefore, $\theta_{a}$ is constant under the assumed conditions.

Tables VII and VIII give similar values of the conventional allowance for higher copper temperatures. Only one value of voltage and insulation thickness is given for reasons just explained.

The results given in these tables give an idea of the probable range in value of the conventional allowance at the limiting copper temperatures for a wide range in values of design factors. These tables could be extended to cover lower and higher core temperatures, and loss ratios, but it is believed that the values chosen are representative of usual design practise, keeping in mind the assumed condition of a fixed copper temperature.

These results are grouped in curve form in Fig. 10. The limits of the cross-hatched area are the maximum and minimum values for each assumed copper temperature rise from Tables VI, VII and VIII. It represents the range of probable values that may be expected in practise.

There have been two propositions advanced as to suitable values of conventional allowance for use in arriving at limiting values of temperature rise for the A. I. E. E. Standards. The first proposition starts with the value of $5 \mathrm{deg}$. now in the Rules assigning this to Class A insulation temperature limits and doubling this for Class B insulation temperature limits. The second proposition doubles these figures. These two propositions are shown by the heavy lines in Fig. 10 . Obviously, the 5 deg. -10 deg. proposition is not adequate to meet the facts, nor is the $10 \mathrm{deg} .-20 \mathrm{deg}$. proposition unduly conservative when it is remembered that the upper limit of values shown in Fig. 10 would be appreciably increased if: (a) allowance were made for increased top coil temperatures caused by the increased eddy current losses in that part of the top coil nearest the air-gap; and (b) if allowance were made for the probability of higher temperatures existing in the individual case than are discovered.

\section{Discussion}

For discussion of this paper see p. 529 . 